\title{
Impacts of adaptation and responsibility framings on attitudes towards climate change mitigation
}

\author{
Rachel A. Howell ${ }^{1,3}$ (D) - Stuart Capstick ${ }^{2}$ • \\ Lorraine Whitmarsh ${ }^{2}$
}

Received: 2 February 2015 / Accepted: 9 February 2016 / Published online: 25 February 2016

(C) The Author(s) 2016. This article is published with open access at Springerlink.com

\begin{abstract}
It is likely that climate change communications and media coverage will increasingly stress the importance of adaptation, yet little is known about whether or how this may affect attitudes towards mitigation. Despite concerns that communicating adaptation could undermine public support for mitigation, previous research has found it can have the opposite effect by increasing risk salience. It is also unclear whether people respond differently to information about mitigation and adaptation depending on whether action is framed as an individual or government responsibility. Using an experimental design, this study sought to examine how public attitudes towards mitigation are influenced by varying climate change messages, and how this might interact with prior attitudes to climate change. UK-based participants $(N=800)$ read one of four texts in a $2 \times 2$ design comparing adaptation versus mitigation information and personal versus governmental action. No main effect was found for adaptation versus mitigation framing, nor for individual action versus government policy, but we did observe a series of interaction effects with prior attitudes to climate change. Mitigation and adaptation information affected participants' responses differently depending on their preexisting levels of concern about climate change, suggesting that mitigation framings may be more engaging for those with high levels of concern, whereas adaptation framings may be more engaging for low-concern individuals. Government mitigation action appears to engender particularly polarised attitudes according to prior concern. Implications for climate change communications are considered.
\end{abstract}

Electronic supplementary material The online version of this article (doi:10.1007/s10584-016-1627-z) contains supplementary material, which is available to authorized users.

Rachel A. Howell

rachel.howell@ed.ac.uk

1 Department of Geography and Earth Sciences, Aberystwyth University, Aberystwyth SY23 3DB, UK

2 School of Psychology, Cardiff University, Cardiff CF10 3AT, UK

3 School of Social and Political Science, The University of Edinburgh, Chrystal Macmillan Building, 15a George Square, Edinburgh EH8 9LD, UK 


\section{Introduction}

The latest Intergovernmental Panel on Climate Change reports reiterate the imperative to address climate change both by reducing emissions that cause it (mitigation) and responding to the impacts (adaptation; IPCC 2014). Early responses to climate change focussed on mitigation, rather than adaptation (Pielke et al. 2007). Some commentators have argued that this focus on mitigation is appropriate given the urgency to cut emissions and the risk that even discussing adaptation could detract from mitigation efforts. Indeed, at least until recently, "discussing adaptation was taboo among environmentalists, on the grounds that it would adversely affect efforts directed at combating climate change itself" (Giddens 2009:162). This concern has been characterised as a moral hazard: analogous to the situation where those who take out insurance are prepared to take greater risks because those risks are borne in part or fully by others (Lin 2013), focussing on adaptation could make people feel mitigation is unnecessary or now too late.

There is growing acceptance, however, that adaptation is critical since further warming is inevitable even if radical emissions reduction policies are implemented (Klein et al. 2007). Many scholars therefore stress the interdependency of adaptation and mitigation efforts (Pielke et al. 2007). Thus it is important that the implementation of adaptation measures does not reduce support for mitigation; without mitigation, the magnitude of climate change is likely to make some adaptation impossible for natural systems and very costly for humans (Klein et al. 2007). To date, however, little work has explored whether an emphasis on adaptation might erode public support for mitigation. As there is likely to be an increase in discussion of adaptation options and media reporting of them, the research reported here aims to shed light on how this might affect public perceptions of climate change and willingness to support and engage in mitigation action. We also consider whether framing information in terms of individual versus government responsibility, and prior climate change attitudes, might influence audience responses to climate change and mitigation options.

\subsection{Communication and perception of climate change responses}

UK media communication of climate change has to date tended to focus on the impacts of climate change (Boykoff 2008; Ereaut and Segnit 2006); insofar as the media has communicated ways of responding to climate change risks, these have more often been in terms of mitigation rather than adaptation (Shanahan 2007). Consistent with media content, public awareness of adaptation responses is much lower than cognizance of mitigation in the UK and other economically-developed countries (Akerlof et al. 2010; Brügger 2010; Whitmarsh 2009) and many people do not feel personally at risk from climate impacts (O'Neill and NicholsonCole 2009) or take any action to protect themselves from flooding or heat stress (Whitmarsh 2008; Wolf et al. 2010). When prompted, individuals who accept the reality of anthropogenic climate change do support policies to adapt to climate change (e.g. Brügger et al. 2015; Vignola et al. 2013) but not if this is instead of mitigation (Capstick 2013a). There may also be a tendency to assume the two are competing strategies, i.e. that there is a forced choice between adaptation or avoidance, with a presumption that 'adapting' is passive, pessimistic, 'defeatist', curative rather than preventative, or implying moral hazard, and therefore negative (Capstick 2013a). This apparent preference for mitigation is consistent with psychological tendencies to view avoiding harm as preferable to compensatory strategies (Baron 2006). 
When people are given the opportunity to carefully deliberate over these two strategies, they appear to be understood in different ways, involving different notions of justice, and as complementary (Klinsky et al. 2012). However, only two studies to our knowledge have examined the synergies or trade-offs between mitigation and adaptation strategies experimentally. Evans et al. (2014) found that framing climate change action around adaptation actually increased support for mitigation. Survey participants were either asked questions on local sea-level rise adaptation strategies and behavioural options, which was intended to prime adaptation considerations (experimental group); or not asked these questions (control group). The former group subsequently expressed significantly higher willingness to undertake mitigation behaviours (e.g. reducing flying), which the researchers explain by the adaptation framing reducing psychological distance in showing how one's own area can be affected, and that the threat is imminent (cf. Milfont 2010). A second study, Carrico et al. (2015), compared the effects of information about novel farming practices (study 1) and reducing air conditioning demand in municipal buildings (study 2), framed around either mitigation or adaptation benefits, on climate change beliefs and policy support. In contrast to Evans et al.'s study, results suggested providing mitigation (not adaptation) information increases support for mitigation. However, while adaptation information did not increase support for mitigation, nor did it reduce support (as the moral hazard argument would suggest). Importantly, though, study 1 found that audience beliefs interacted with information provided; unlike liberals and conservatives, political moderates were more positive about the technology when told it was for adaptation purposes. This highlights the importance of disaggregating audience responses to climate change information, rather than examining mean responses (cf. Kahan et al. 2015). Neither of these studies, however, examined how prior attitudes to climate change influence responses to adaptation versus mitigation action despite extensive evidence that these can produce divergent reactions (e.g., Corner et al. 2012); nor did they examine a wide range of adaptation and mitigation options, instead focussing on a single sector or type of climate change impact in each study.

\subsection{Moral hazard}

Moral hazard has been used to refer to a circumstance where an individual ignores risks or takes more risks because the burden of paying for them is borne by others or has been reduced in other ways, as exemplified in the case of taking fewer precautions after taking out insurance (Lin 2013). Research on risk compensation behaviours shows that health and safety-related behaviours may change in perverse ways in the face of risk reduction measures; e.g. motorists driving less carefully following the introduction of mandatory seat belts (Blomquist 1988). While there are various contexts in which such risk compensation behaviours have been observed, overall the effect appears to be rather unpredictable and the evidence base is mixed (Levym and Miller 2000). Furthermore, as Lin (2013: 689) notes, both moral hazard and risk compensation theories assume that "people in general are economically rational, that risktaking is a deliberate act, and that reduced exposure to risk provides incentives for riskier conduct", whereas psychological research has shown people to respond to risk in noneconomically rational ways. Consequently, the assumption that climate change adaptation policy and communication might erode mitigation support if adaptation is perceived as reducing climate change risks may be unfounded. Indeed, the limited research to date on climate change adaptation and mitigation responses (Evans et al. 2014; Carrico et al. 2015) finds no support for a moral hazard or risk compensation phenomenon; on the contrary, it 
demonstrates partial support for a 'risk as salience' relationship (Carrico et al. 2015) whereby at least for some audiences - framing information in adaptation terms appears to make the risks of climate change more personally relevant, reducing psychological distance. In this research, we consider whether communicating climate change adaptation acts to produce moral hazard or increase psychological proximity of climate risks.

\subsection{Costs versus benefits and responsibility for action}

Another body of literature that calls into question the moral hazard argument is that of risk perception. Risk judgements often involve weighing up costs and benefits associated with hazards, with perceived risk typically inversely related to perceived benefits (Slovic 2000). For example, Poortinga and Pidgeon (2003) found that acceptability of genetic testing risks was higher than for those associated with genetically-modified food, consistent with the ratings of the benefits associated with these different technologies. From this perspective, we might expect differences in climate change attitudes according to whether an adaptation or a mitigation frame is emphasised, if this affected perceptions of costs and benefits of action. Whereas much climate change communication implicitly or explicitly includes a mitigation behaviour change message (Ereaut and Segnit 2006) and a moral imperative to make individual sacrifices for the common good (Hulme 2009), adaptation messages sometimes more directly link action to personal benefit, and may appeal to a practical rather than altruistic motivation. In other words, consistent with social dilemma theory, cutting one's energy use may be resisted as this will not directly bring climate change benefits to the individual, whereas taking protective measures like installing flood defences could do so (Capstick 2013b). Furthermore, since many carbon-intensive behaviours (e.g. driving, international travel, meat consumption) are closely tied to identity, changing these is often strongly resisted (Whitmarsh 2009). Consequently, there is the potential for some adaptation-framed messages to be more acceptable than mitigation-framed ones that imply costs for little or no direct personal benefit. In addition, since adaptation does not require belief in anthropogenic climate change (only that the climate is changing) "a frame of adaptation pushes the discussion of climate change beyond frames that question its prevalence" and thus may engage even sceptical audiences (Rademaekers and Johnson-Sheehan 2014).

The scale at which these measures are conceived may also make a difference: individuallevel adaptation measures (e.g. buying sand bags) have the potential to be less acceptable than collective-level measures (e.g. coastal flood defences) where costs and effort are shared. Consequently, while framing impacts as more proximal may in theory reduce psychological distance (Evans et al. 2014), framing solutions in terms of personal responsibility (as opposed to societal or governmental responsibility) may create psychological reactance and reduce willingness to engage in responses. This is supported by research that finds different predictors of policy support versus individual action for both adaptation and mitigation (Brügger 2010; Sposato et al. 2014). Experimental research also shows that framing climate change responses in terms of the need for individual behaviour change, which may be considered a more identity-threatening message, reduces climate change belief, concern and willingness to act compared to a message which is framed around broader policy and industry action (Xenias et al. submitted). Similarly, Spence and Pidgeon (2010) found that asking individuals to consider social aspects of mitigation resulted in more positive attitudes than the consideration of individual aspects. This is consistent with both the risk perception literature (Slovic 2000), and the sizeable literature on motivated reasoning - the tendency of individuals to process 
information and make decisions based on their pre-existing motives or goals (Kunda 1990). Consequently, it may be expected that information about climate change that stresses individual responsibility may reduce support for action, with this effect likely to be greater in the case of mitigation than adaptation.

\subsection{The role of prior attitudes}

The motivated reasoning literature further suggests that psychologically defensive reactions such as risk denial vary according to prior attitudes. Social psychological research shows prior attitudes influence information processing and potentially polarise responses (e.g. Lord et al. 1979). For example, individuals with conservative values/worldviews (Republicans/hierarchical individualists) are more likely to accept the reality of anthropogenic climate change after reading about technological responses, and more likely to reject it if the solutions discussed mention emissions restrictions (Campbell and Kay 2014; Kahan et al. 2015). Consequently, we would expect that those with lower levels of concern about climate change, which is often related to liberal/ conservative ideology (Zia and Todd 2010), might be less defensive towards climate change messages framed around adaptation rather than mitigation, since while both types of response might involve new technologies, only mitigation is associated with reducing emissions.

\subsection{Current study}

In sum, research is needed to consider how public attitudes are affected by information about adaptation and mitigation, while also exploring how perceived responsibility for action may affect views and responses, as well as how prior beliefs may account for different reactions to this information. To date, no studies have explored these three aspects together.

First, we examine whether exposure to information about climate change adaptation affects attitudes towards mitigation. On the one hand, it has been suggested the former could erode support for the latter due to a moral hazard or risk compensation interpretation. On the other hand, the limited empirical evidence available suggests that the reverse may be the case; that consideration of adaptation responses could increase support for mitigation by increasing risk salience (Evans et al. 2014; Xenias et al. submitted).

Secondly, we consider the impact of responsibility framing on attitudes towards mitigation. Consistent with motivated reasoning and risk perception research, framing climate change solutions around personal action seems likely to reduce support for such action since the information may be perceived to be more threatening (Xenias et al. submitted) or costly relative to the associated benefits (Slovic 2000).

Finally, consistent with biased assimilation research, we expect that those who are less concerned or sceptical about climate change will be particularly resistant to messages framed around mitigation, because these imply the need for regulation of emissions (cf. Campbell and Kay 2014; Kahan et al. 2015).

The current study uses an experimental design to test the effects of differently framed messages on perceptions of climate change and attitudes towards mitigation. Consistent with our hypotheses, we focus on the effects of two independent experimental variables on attitudes to climate change mitigation (dependent variable): (i) the type of response emphasised (mitigation versus adaptation); and (ii) the responsibility for action (personal versus government action framings). Interaction effects were examined with respect to a third (nonexperimental) independent variable, participants' prior attitudes to climate change. 


\section{Methods}

\subsection{Participants}

Participants for the study were 800 members of the UK public sampled from an online research panel (maintained by market research company ResearchNow) across the UK between 28 July and 4 August 2014. The sample was $53 \%$ female, with a mean age of 46 years $(\mathrm{SD}=17.5$ years). Quota sampling was used to ensure that age, gender, socioeconomic characteristics and region were broadly representative of the UK population.

\subsection{Study design and framing}

The study utilised a two-way experimental design, in which participants were allocated to one of four experimental conditions, randomly except that quotas were used to ensure that the groups did not differ significantly in terms of age or gender. The experimental manipulation entailed assigning participants simultaneously to either a mitigation or adaptation condition, and also to a personal or governmental response condition. This was achieved through provision of texts that framed climate change responses in these terms. All participants received the following preliminary text:

In the latest UN report on climate change, scientists say that they are now almost $100 \%$ certain that climate change is mainly caused by human activities.

Climate change is expected to have a range of effects. The UK faces increased risks of more extreme storms, raised sea levels, heatwaves and droughts due to climate change.

Many more people could be at risk of flooding, heat-related health problems (especially young children and elderly people) and water shortages.

Participants then received additional information according to their assigned condition (see Table 1, Supplementary Material). This was designed to emphasise either mitigation or adaptation as a response to climate change; and additionally, to emphasise either individual or government action. In other respects, the texts were designed to be equivalent in format, length and tone. Information used in the manipulations was derived from scientific reports and government documents relating to climate change impacts and adaptation, including climate projections by the Met Office (2011), The National Adaptation Programme (Defra 2013) and the Heatwave Plan for England (PHE 2014), as well as commonly discussed government and personal mitigation options.

\subsection{Measures and procedures}

Participants completed the experiment online. Following the provision of consent and demographic information, they were asked to indicate the extent to which they worried about climate change (from 0 'not at all' to 10 'extremely') and how important the issue of climate change was to them personally (from 0 'not at all' to 10 'extremely'). These two measures were combined to form a climate change concern score (Spearman-Brown coefficient .944 indicates high reliability of this scale). Mean climate change concern scores were close to the mid-point (5.51, $\mathrm{SD}=2.49)$.

Participants were randomly allocated to one of the four experimental conditions and read one of the four framing texts described above. Each participant then completed a short exercise 
designed to promote recall and enhance the experimental manipulation. This entailed being asked to select from a list of possible actions that individuals/government could take to adapt to/mitigate climate change, commensurate with the condition to which they had been assigned. To avoid confusion and reinforce the manipulation, they were then given the correct answers to this question.

Next, a manipulation check was administered. Participants were asked to state the extent to which they agreed with the following statements: 'The article gave relevant information about how to reduce emissions that cause climate change'; 'The article gave relevant information about how to cope with the effects of climate change'; 'The article gave relevant information about how individuals can take action'; 'The article gave relevant information about how the UK government can take action' (five point scales were used from 'strongly disagree' to 'strongly agree'). Independent samples t-tests showed that participants in the relevant condition (as a group) were significantly more likely to agree with the corresponding statement $(p<.001$ in each case).

The study utilised six dependent variables intended to gauge attitudes towards climate change and towards action at personal and policy levels. Each of these variables was comprised of a multiple-item scale with good to excellent reliability, corresponding to belief in the reality of climate change $(\alpha(4)=.747)$; willingness to undertake personal mitigation action $(\alpha(12)=.873)$; support for mitigation policies $(\alpha(12)=.888)$; perceived threat of climate change $(\alpha(5)=.768)$; general attitudes towards mitigation $(\alpha(4)=.921)$; and moral hazard (the extent to which respondents stated they were less concerned about mitigation if adaptation measures were taken by the UK government) $(\alpha(10)=.815)$. Table 2 a (Supplementary Material) details the scales and items used for each of these six measures.

The six dependent variables were moderately correlated (typically at around $r=.5$ ) as shown in Table 2b (Supplementary Material). Given the high correlation $(r=.73)$ obtained between the 'willingness to take action' and 'support for mitigation policy' scales, principal components analysis using oblique (oblimin) rotation was performed to assess whether these were conceptually distinct. The pattern matrix obtained indicated that items from these two scales loaded on separate factors. A first factor explaining $38 \%$ of variance was comprised of items from the 'support for mitigation policy' scale relating to imposition of costs and restrictions through policy (e.g. increased fuel taxation); a second factor explaining a further $10 \%$ of variance was comprised of items from the 'willingness to take action' scale corresponding to simple behavioural changes (e.g. turning down one's heating). Three further factors explaining around $5 \%$ variance each were likewise conceptually distinct in terms of personal mitigation intentions or support for mitigation policy. Therefore we retained these two scales as separate dependent variables for further analyses.

\section{Results}

There were no significant differences between the four experimental groups in terms of gender, age, region, socioeconomic group, or income; nor were there significant differences in prior concern about climate change between the groups.

We carried out regression analysis using mean-centred predictor variables, to assess effects for each of the dependent variables. We examined main effects of the two framings used (i.e. individual/government and adaptation/mitigation) and of pre-existing concern; the model also incorporated interactions between pre-existing concern and these framings, and three-way 
interactions (between the two framings and pre-existing concern). The proportion of variance accounted for by the models was between 30 and $40 \%$ in each case, with the exception of the moral hazard measure which accounted for only around $15 \%$ of variance. Model statistics are given in Table 1.

Unsurprisingly, we observed a large main overall effect of climate change concern in each case. Under all conditions, those participants with higher pre-existing climate change concern indicated greater belief in, and sense of threat from, climate change, more positive attitudes towards mitigation and willingness to take and support action, and a lower 'moral hazard' score than those who were less concerned.

With respect to framing condition, no significant main effects were obtained; that is, there was no evidence to suggest that, ceteris paribus, the presentation of information in terms of adaptation/mitigation or an individual/government response led to differing scores for any of the dependent variables. Likewise, no effects were observed for the two-way interactions between the framing conditions.

For three of the six dependent variables, we did however observe significant interaction effects between pre-existing concern and the adaptation/mitigation framing. An adaptation framing was associated with higher level of belief in the reality of climate change - relative to the mitigation framing - for those who were less concerned about climate change. This pattern was also observed for the measure of willingness to take action on climate change, and support for mitigation policies. For belief in the reality of climate change, we also observed an interaction between individual/government framing and pre-existing concern. The individual framing was associated with higher scores for those who were less concerned about climate change, relative to the government framing.

Further inspection of three-way interactions suggested that additional effects for four of six dependent variables were obtained - over and above those described above - under particular combinations of the two framings, and contingent upon pre-existing concern.

In each case, the framing effect of the mitigation text was accentuated where combined with the government framing. This applied to the dependent measures of belief in the reality of climate change, willingness to take action, perceived threat of climate change, and attitudes towards mitigation. For those with lower levels of pre-existing concern, the combined mitigation-plus-government framing was associated with lower scores on each dependent variable, relative to the combined adaptation-plus-government framing.

Interaction plots illustrating this pattern of findings for the measure of belief in the reality of climate change are shown in Fig. 1. Plot 1a shows the interaction between climate change concern and adaptation/mitigation framing (irrespective of individual/government framing). Plots $1 \mathrm{~b}$ and $1 \mathrm{c}$ show the pattern of interactions between concern and the adaptation/mitigation framing separately for those presented with an individual or government framing; this indicates that the latter framing combination has a more pronounced effect upon the dependent variable. In Fig. 2 we show the interaction plots in the same format for the measure of willingness to act. Finally, in Fig. 3 we show the interactions for the measure of perceived threat of climate change: here, no significant interaction is obtained for the adaptation/mitigation framing with pre-existing concern; however, a three-way interaction is observed. For each of Figs. 1, 2 and 3 'high' concern participants correspond to those with scores greater than one standard deviation above the mean for pre-existing concern; 'low' concern participants have scores less than one standard deviation below the mean; 'medium' concern participants are within one standard deviation of the mean. 
Table 1 Linear regression results

Independent variable / condition

B (S.E.)

$\beta$

$\mathrm{p}$ value

DV: Belief in the reality of climate change (adjusted $\mathrm{R}^{2}=.31$ )

Climate change concern

$\begin{array}{rrc}.18(.01) & .55 & <.001 \\ .06(.05) & .04 & .22 \\ .02(.05) & .01 & .72 \\ -.05(.02) & -.08 & .01 \\ -.05(.02) & -.07 & .02 \\ .08(.09) & .03 & .38 \\ .08(.04) & .06 & <.05 \\ & & \\ .19(.01) & .63 & <.001 \\ -.02(.04) & -.02 & .55 \\ .02(.04) & .02 & .54 \\ -.06(.02) & -.09 & <.001 \\ .01(.02) & .02 & .39 \\ -.08(.08) & -.03 & .31 \\ .07(.03) & .06 & .04\end{array}$

Framing (1) Adaptation versus mitigation ${ }^{\mathrm{a}}$

Framing (2) Individual versus government action framing ${ }^{\mathrm{b}}$

Framing (1)* Climate change concern

Framing (2)* Climate change concern

Framing (1) * Framing (2)

Framing (1) * Framing (2) * Climate change concern

DV: Willingness to take action (adjusted $\mathrm{R}^{2}=.40$ )

Climate change concern

Framing (1) Adaptation versus mitigation

Framing (2) Individual versus government action framing

Framing (1) * Climate change concern

Framing (2)* Climate change concern

Framing (1) * Framing (2)

Framing (1) * Framing (2) * Climate change concern

DV: Support for mitigation policies (adjusted $\mathrm{R}^{2}=.38$ )

Climate change concern

$.19(.01)$

.61

$<.001$

Framing (1) Adaptation versus mitigation

$-.04(.04)$

$-.03$

.35

Framing (2) Individual versus government action framing

$-.03(.04)$

$-.02$

.50

Framing (1) * Climate change concern

$-.06(.02)$

$-.09$

$<.01$

Framing (2)* Climate change concern

$.02(.02)$

.02

.39

Framing (1) * Framing (2)

Framing (1) * Framing (2) * Climate change concern

$.02(.09)$

.85

$.06(.03)$

.01

.08

DV: Perceived threat of climate change (adjusted $\mathrm{R}^{2}=.41$ )

Climate change concern

$.19(.01)$

.64

$<.001$

Framing (1) Adaptation versus mitigation

$.01(.04)$

.78

$.00(.04)$

.01

.94

Framing (1)* Climate change concern

$-.02(.02)$

.00

.35

Framing (2)* Climate change concern

$-.02(.02)$

$-.03$

.16

$-.09(.08)$

$-.04$

.28

Framing (1) * Framing (2)

Framing (1) * Framing (2) * Climate change concern

$.09(.03)$

$-.03$

$<.01$

DV: Attitudes towards mitigation (adjusted $\mathrm{R}^{2}=.34$ )

Climate change concern

$.21(.01)$

$<.001$

Framing (1) Adaptation versus mitigation

$-.01(.05)$

.58

.85

Framing (2) Individual versus government action framing

$-.08(.05)$

$-.01$

.12

$-.01(.02)$

$-.04$

.50

Framing (1)* Climate change concern

$.01(.02)$

$-.02$

.77

Framing (1) * Framing (2)

$.02(.10)$

.85

$.10(.04)$

.02

DV: Moral hazard (adjusted $\mathrm{R}^{2}=.15$ )

Climate change concern

$-.10(.01)$

$<.001$

Framing (1) Adaptation versus mitigation

$.01(.04)$

$-.39$

.78

$.02(.04)$

.01

.60 
Table 1 (continued)

\begin{tabular}{lcrr}
\hline Independent variable / condition & B (S.E.) & $\beta$ & p value \\
\hline Framing (1) * Climate change concern & $.02(.02)$ & .03 & .33 \\
Framing (2) * Climate change concern & $.00(.02)$ & -.01 & .88 \\
Framing (1)* Framing (2) & $-.02(.08)$ & -.01 & .79 \\
Framing (1)* Framing (2) * Climate change concern & $-.03(.03)$ & -.03 & .38 \\
\hline
\end{tabular}

${ }^{\mathrm{a}}$ adaptation +.5 vs. mitigation $-.5,{ }^{\mathrm{b}}$ individual +.5 vs. government -.5

In sum, our results suggest that framing information in terms of adaptation or mitigation had the potential to affect participants' attitudes differently, depending upon their pre-existing levels of concern about climate change. Overall, mitigation framings tended to prompt stronger responses for high-concern participants, with adaptation framings prompting stronger responses for low-concern participants. Additionally, our results suggest that a combined mitigation-plus-government framing may be particularly disengaging for those who have low pre-existing levels of concern.

\section{Discussion}

\subsection{Summary}

It is necessary to both mitigate and adapt to climate change, but adaptation has featured relatively little in public discourse in the UK thus far. Despite concerns that communicating adaptation could undermine public support for mitigation, there has been very little prior research that has examined this empirically; such work as has been done suggests that it can have the opposite effect by reducing psychological distance. It is also unclear how climate change messages framed around different scales of responsibility (individual versus government) as well as different types of solutions (i.e. mitigation versus adaptation) might affect attitudes. Using an experimental design, the current study sought to examine how public attitudes towards mitigation are influenced by different types of climate change action messages, and how this might interact with participants' prior attitudes to climate change.

In contrast to previous identity threat research (Xenias et al. submitted), we did not find a main effect for responsibility framing of climate change solutions (i.e. individual responses versus government policy). This could possibly be because although responsibility for action was located with government in our 'government policy' frames, several of the examples given would nevertheless impact on individuals, unlike the industry action and technological innovations discussed by Xenias et al.

Also in contrast to previous research (Evans et al. 2014), and representing a key finding from the present study, we did not find that framing climate change around adaptation generated more support for mitigation uniformly across the sample when compared to a mitigation message. Rather, as Carrico et al. (2015, study 1) find, individuals' prior beliefs appear to determine how they process climate change adaptation information. Similarly consistent with Carrico et al. (2015), and contrary to the moral hazard argument, we did not find that support for climate change mitigation is necessarily undermined by an adaptation message (compared to a mitigation message). Our diverging results with Evans et al. (2014) 
a

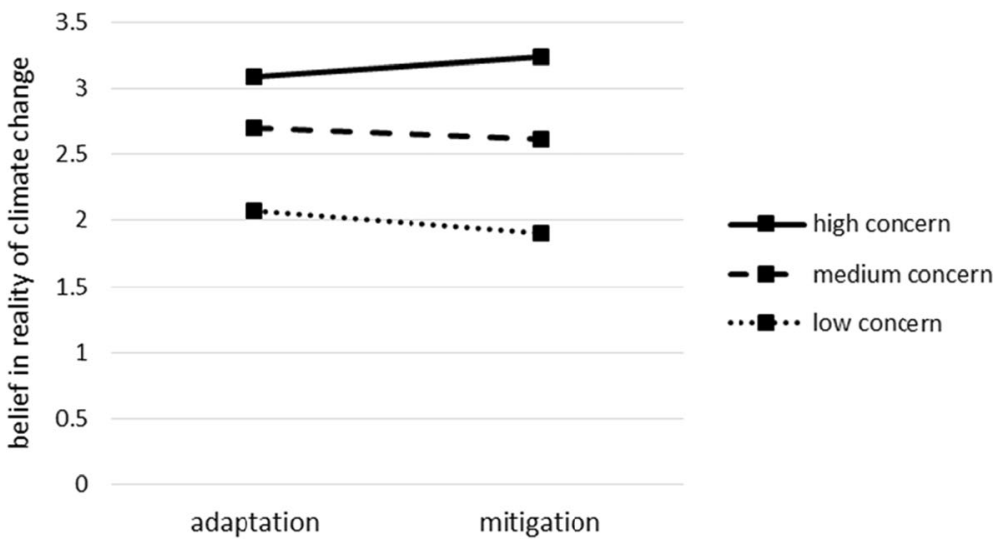

b 'individual' framing condition

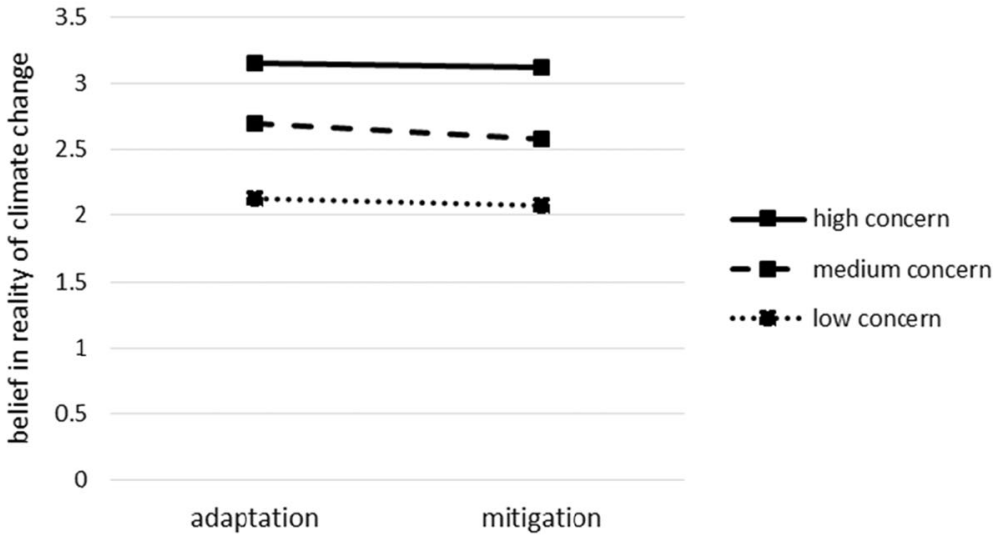

\section{C 'government' framing condition}

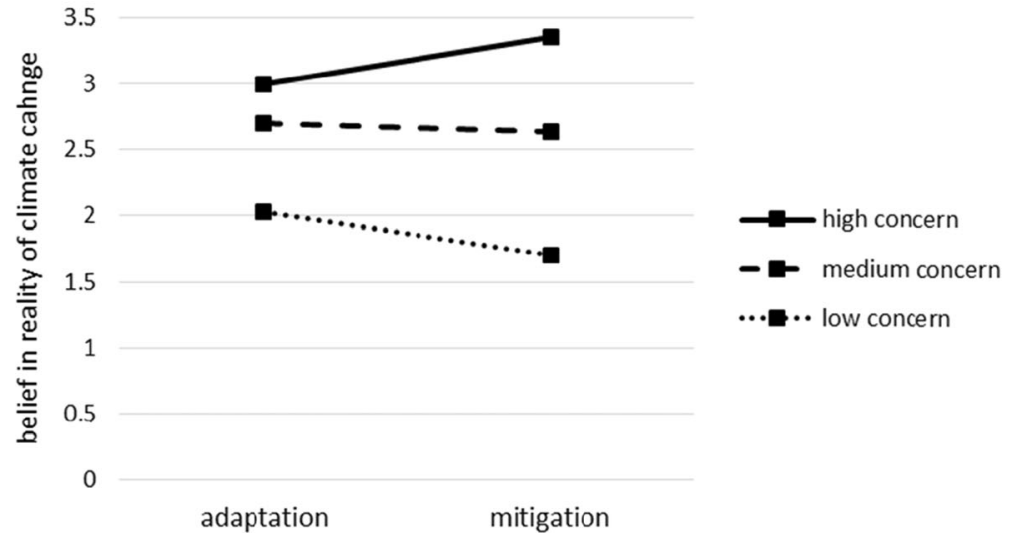

Fig. 1 Interaction between adaptation/mitigation framing and pre-existing concern for belief in the reality of climate change a irrespective of individual/government framing; b individual framing only; c government framing only 
a

3.5

3
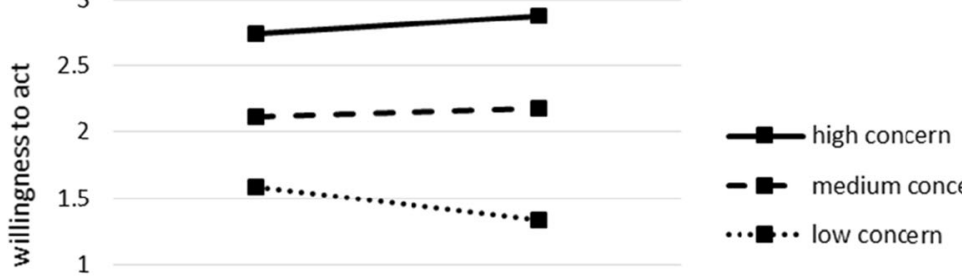

- E medium concern

...… low concern

0.5

0

adaptation

mitigation

b 'individual' framing condition

3.5

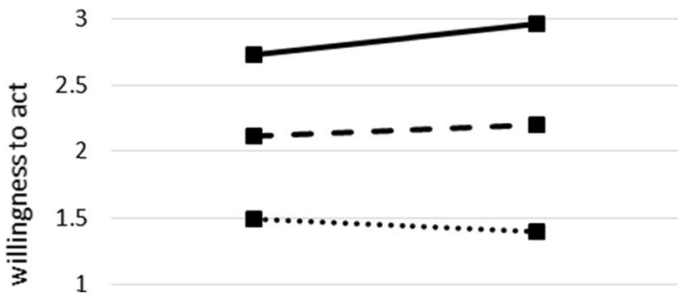

$\longrightarrow$ high concern

- - medium concern

...… low concern

0.5

0
adaptation
mitigation

\section{C 'government' framing condition}
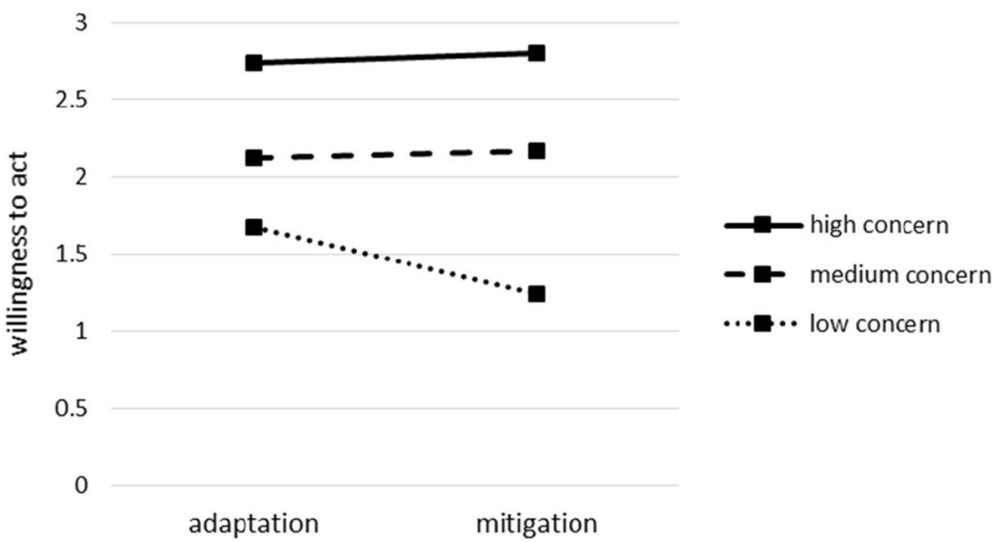

Fig. 2 Interaction between adaptation/mitigation framing and pre-existing concern for willingness to act on climate change a irrespective of individual/government framing; b individual framing only; c government framing only 
a

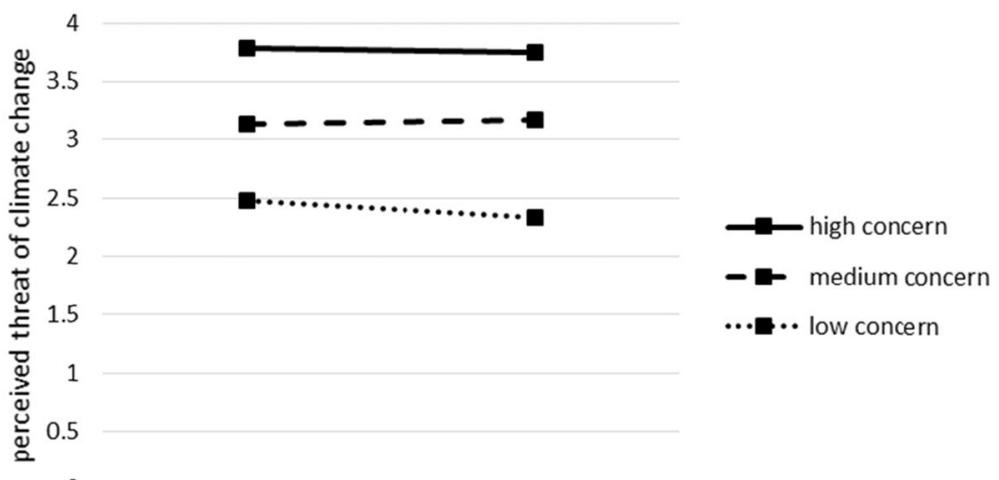

adaptation mitigation

\section{b 'individual' framing condition}

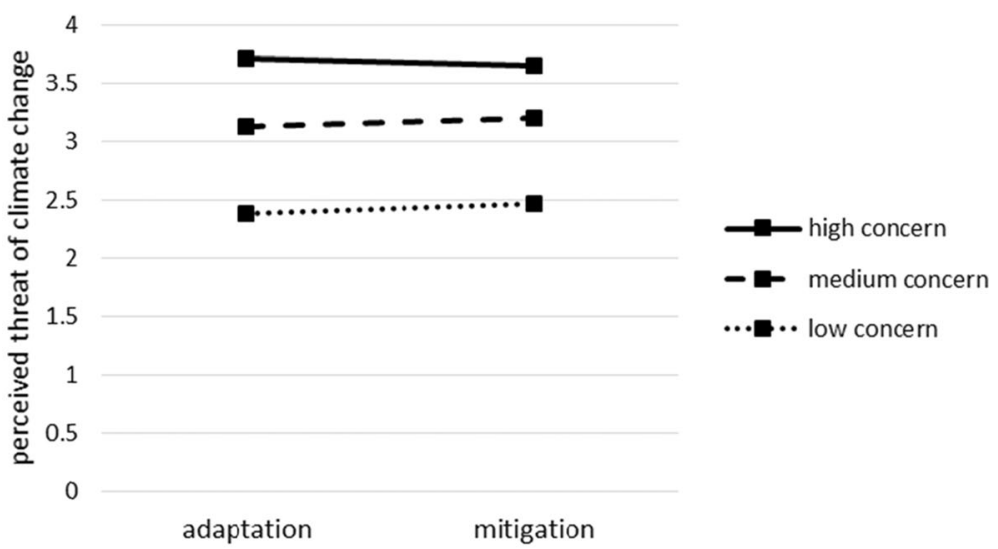

\section{C 'government' framing condition}

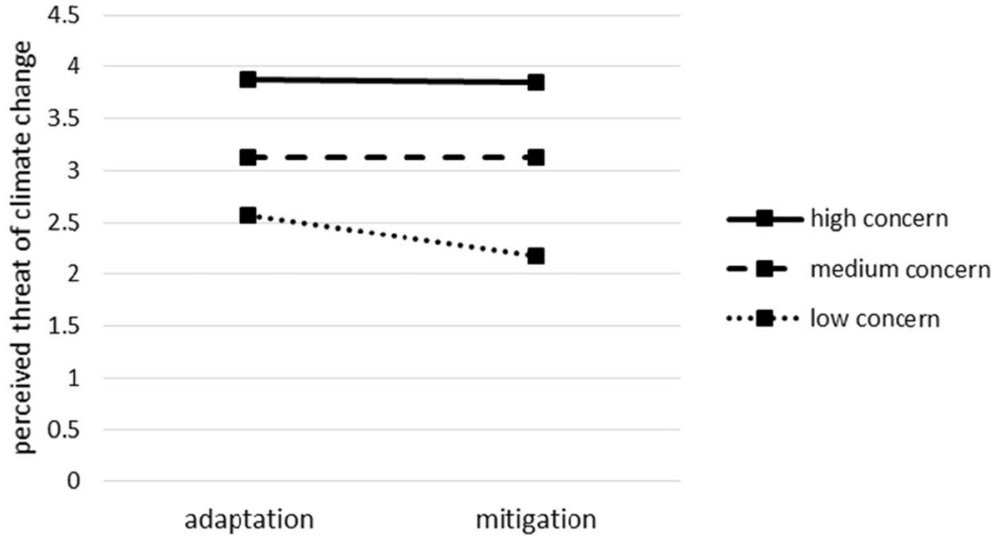

Fig. 3 Interaction between adaptation/mitigation framing and pre-existing concern for perceived threat of climate change a irrespective of individual/government framing; b individual framing only; c government framing only 
may be due to the different framings and experimental manipulations used in each case; while their study used a questionnaire on sea-level rise to prime adaptation considerations, we communicated adaptation through information provided about country-specific climate change impacts. It may be that the specificity of the risk (local sea-level rise versus national climate change impacts), the relative vividness of impacts presented by Evans et al., or the nature of the prime (survey versus text) is relevant here.

While we did not find a main effect of adaptation versus mitigation framing, consistent with biased assimilation research (Campbell and Kay 2014; Corner et al. 2012; Kahan et al. 2015) we did find an interaction effect with prior attitudes to climate change. Our findings suggest that emphasising mitigation or adaptation as responses to climate change can have different consequences for attitudes depending on whether or not a person has pre-existing concern about climate change. Adaptation framings appear to be more engaging for those with low levels of concern, whereas mitigation framings appear to be more engaging for those with high levels of concern. The most striking consequence of this is that participants' belief in the reality of climate change itself was affected differently by the framings, depending on whether study participants were concerned in advance about climate change. Emphasising responses to climate change that were adaptive appeared to affirm belief in its reality for low-concern participants more than did an emphasis on mitigation responses. We predicted that the lowconcern participants would be less threatened by the adaptation framings than by the mitigation framings since they may be resistant to emissions reduction and behaviour change messages; while for high-concern participants, mitigation is more closely aligned than adaptation with how they think climate change should be tackled. Critically, this result appears to support a motivated reasoning interpretation since belief in climate change, as well as policy and behaviour change support, was influenced by the framing. In other words, pairing climate change risk information with a mitigation behaviour change message has the potential to lead disengaged audiences to deny the risk as well as reduce their support for action.

Having said that, it could be that our results were influenced by the particular actions we suggested in each manipulation text as much as by the adaptation versus mitigation framings per se. Although we tried to make the texts as comparable as possible, including both behaviour change and technological solutions in each 'personal action' text, and technological, regulatory, and investment solutions in each 'government action' text, the mitigation texts do mention reducing emissions that cause climate change, and may be read as involving more behavioural change/regulatory solutions than the adaptation texts. Hence they may have been less attractive to respondents with low prior climate change concern for that reason (cf. Campbell and Kay 2014; Kahan et al. 2015).

A combined mitigation-plus-government action framing seemed to be particularly disengaging for low concern participants. This may be because those who are less concerned about climate change are more likely to have right-of-centre political views, leading to objections to regulatory action (Campbell and Kay 2014); this could be more pronounced for mitigation than adaptation if the former is perceived as interfering in lifestyle choices more than the latter (which may have been the effect of the options we presented in our manipulation texts).

\subsection{Implications}

Our results are preliminary, and we stress the need for further research. The interaction effects we observe are relatively weak in comparison to the main effect of pre-existing concern about 
climate change on the dependent measures. We caution therefore that our findings should be considered experimental evidence that the consequences of framing in terms of adaptation versus mitigation may differ according to prior attitudes, rather than evidence that these consequences are likely to be particularly pronounced.

That said, these findings reinforce the substantial body of evidence that demonstrates a need for differential communication strategies according to audience type. A growing body of work suggests that messages should be tailored according to the understanding, beliefs and values of the audience (Moser 2010), and our study suggests that this includes whether to stress adaptation or mitigation if the aim is to promote (support for) mitigation action - or at least if there is a concern that this should not be undermined. Mitigation appears to be a strategy supported more by those with high concern about climate change; whereas those less concerned may find adaptation strategies less threatening and more aligned with their beliefs.

The results of the study suggest that organisations working with people who are already engaged with climate change might consider emphasising mitigation, in order to avoid potential negative effects of adaptation discourses. By contrast, policymakers and organisations seeking to involve individuals or groups who are disengaged with climate change might do better to begin by discussing adaptation as this potentially could engage this particular public more. The most difficult decisions will arise for those who wish to create climate change communications for an undifferentiated general public, who will have to weigh up the possible positive and negative effects of including information about adaptation. Notwithstanding the need for such organisations to convey critical information about adaptation (e.g. to encourage uptake of flood prevention measures) it should be borne in mind how adaptation messaging may affect attitudes towards climate change more broadly. It may be that stressing adaptation could raise levels of belief in the reality of climate change and engagement with the issue among people who are currently unconcerned. Although an emphasis on adaptation risks reducing support from those who are concerned, their concern will quite possibly lead them to seek and be receptive to information from other sources, many of which emphasise mitigation. Thus more might be gained overall than lost in diversifying the discourses about responses to climate change.

\subsection{Limitations and future research}

Our study did not include actual behavioural measures (e.g. energy use), relying instead on stated willingness to take personal actions and professed support for mitigation policies. While such attitudinal measures are important indicators of behavioural propensity (Ajzen 1991), there is only a partial correspondence between attitudes and behaviour in respect of climate change action and this is weaker for private-sphere action (e.g. energy conservation) than for public-sphere action (e.g. policy support; Stern 2000; Whitmarsh 2009). Future research should include direct measures of mitigation action, as well as attitudes and intentions.

Further research is also needed to determine the strength and generality of these findings across different ways of describing future climate change scenarios and responses to them. For example, there is a need to test whether the results differ if mitigation messages that stress technological solutions more than behavioural change, and/or adaptation messages that imply more government regulation, are used.

The three-way interaction effects obtained suggest that the two types of framing might amplify or suppress each other, but this finding would benefit from further research. 
Other avenues for future research include exploring different predictors and mediators of mitigation support in relation to adaptation frames; these could include efficacy, perceived responsibility for adaptation, risk perception and place identity (Adger et al. 2012; Brügger 2010; Fresque-Baxter and Armitage 2012; Semenza et al. 2011).

Finally, there remains much work to be done on the impacts of different discourses/framing of information on attitudes towards adaptation. If we are to successfully respond to the challenge of climate change, public support for both mitigation and adaptation at a variety of scales will be necessary.

Acknowledgments Thanks to three anonymous reviewers, and to participants for their time. This research was funded by a British Academy/Leverhulme Small Research Grant awarded to Rachel Howell.

Open Access This article is distributed under the terms of the Creative Commons Attribution 4.0 International License (http://creativecommons.org/licenses/by/4.0/), which permits unrestricted use, distribution, and reproduction in any medium, provided you give appropriate credit to the original author(s) and the source, provide a link to the Creative Commons license, and indicate if changes were made.

\section{References}

Adger WN, Quinn T, Lorenzoni I, Murphy C, Sweeney J (2012) Changing social contracts in climate change adaptation. Nat Clim Chang. doi:10.1038/NCLIMATE1751

Ajzen I (1991) The theory of planned behavior. Organ Behav Hum Decis Process 50:170-211

Akerlof K, DeBono R, Berry P et al (2010) Public perceptions of climate change as a human health risk: surveys of the United States, Canada and Malta. Int J Environ Res Public Health 7:2559-2606

Baron J (2006) Thinking about global warming. Clim Chang 77:137-150

Blomquist GC (1988) The regulation of motor vehicle and traffic safety. Springer, New York

Boykoff MT (2008) The cultural politics of climate change discourse in UK tabloids. Pol Geogr 27:549-569

Brügger A (2010) Support for mitigation and adaptation - policies and personal intentions to act: explorations in the UK and in Switzerland. Research Student Conference on Human Behaviour and Climate Change, Cardiff, UK

Brügger A, Morton TA, Dessai S (2015) Hand in hand: public endorsement of climate change mitigation and adaptation. PLoS ONE 10:e0124843

Campbell TH, Kay AC (2014) Solution aversion: on the relation between ideology and motivated disbelief. J Pers Soc Psychol 107:809-824

Capstick S (2013a) The Psychology of climate change adaptation: prevention is better than cure? AGU Chapman Conference on Climate Change Communication, Colorado, USA

Capstick S (2013b) Public understanding of climate change as a social dilemma. Sustainability 5:3484-3501

Carrico AR, Truelove HB, Vandenbergh MP, Dana D (2015) Does learning about climate change adaptation change support for mitigation? J Environ Psychol 41:19-29

Corner A, Whitmarsh L, Xenias D (2012) Uncertainty, scepticism and attitudes towards climate change: biased assimilation and attitude polarisation. Clim Chang 114:463-478

Defra (2013) The national adaptation programme: making the country resilient to a changing climate. Department for Environment, Food and Rural Affairs, London

Ereaut G, Segnit N (2006) Warm words: how are we telling the climate story and can we tell it better? Institute for Public Policy Research, London

Evans L, Milfont TL, Lawrence J (2014) Considering local adaptation increases willingness to mitigate. Glob Environ Chang. doi:10.1016/j.gloenvcha.2013.1012.1013

Fresque-Baxter JA, Armitage D (2012) Place identity and climate change adaptation: a synthesis and framework for understanding. WIREs Clim Change 3:251-266

Giddens A (2009) The politics of climate change. Polity Press, Cambridge

Hulme M (2009) Why we disagree about climate change: understanding controversy, inaction and opportunity. Cambridge University Press, Cambridge

IPCC (2014) Climate change 2014: synthesis report. Available online at: http://www.ipcc.ch/pdf/assessmentreport/ar5/syr/SYR_AR5_LONGERREPORT_Corr2.pdf 
Kahan DM, Jenkins-Smith HC, Tarantola T, Silva CL, Braman D (2015) Geoengineering and the science communication environment: a cross-cultural experiment. Ann Am Acad Pol Soc Sci 658:192-222

Klein RJT, Huq S, Denton F et al (2007) Inter-relationships between adaptation and mitigation. In: Parry ML, Canziani OF, Palutikof JP, van der Linden PJ, Hanson CE (eds) Climate change 2007: impacts, adaptation and vulnerability, Contribution of Working Group II to the Fourth Assessment Report of the Intergovernmental Panel on Climate Change. Cambridge University Press, Cambridge

Klinsky S, Dowlatabadi H, McDaniels T (2012) Comparing public rationales for justice trade-offs in mitigation and adaptation climate policy dilemmas. Glob Environ Chang 22:862-876

Kunda Z (1990) The case for motivated reasoning. Psychol Bull 108:480-498

Levym DT, Miller T (2000) Review: risk compensation literature - the theory and evidence. J Crash Prev Inj Control 2:75-86

Lin AC (2013) Does geoengineering present a moral hazard? Ecol Law Q 40:673-712

Lord CG, Ross L, Lepper MR (1979) Biased assimilation and attitude polarization: the effects of prior theories on subsequently considered evidence. J Pers Soc Psychol 37:2098-2109

Met Office (2011) Climate: observations, projections and impacts, United Kingdom. Exeter, UK

Milfont TL (2010) Global warming, climate change and human psychology. In: Corral-Verdugo V, GarcíaCadena $\mathrm{CH}$, Frías-Arment M (eds) Psychological approaches to sustainability: current trends in theory, research, and practice. Nova Science, New York, pp 19-42

Moser SC (2010) Communicating climate change: history, challenges, process and future directions. WIREs Clim Change 1:31-53

O'Neill SJ, Nicholson-Cole S (2009) "Fear won't do it": promoting positive engagement with climate change through visual and iconic representations. Sci Commun 30:355-379

PHE (2014) Heatwave plan for England 2014: protecting health and reducing harm from severe heat and heatwaves. Public Health England, London

Pielke R Jr, Prins G, Rayner S, Sarewitz D (2007) Lifting the taboo on adaptation. Nature 445:597-598

Poortinga W, Pidgeon N (2003) Public perceptions of risk, science and governance: main findings of a British survey of five risk cases. University of East Anglia and MOR, Norwich

Rademaekers JK, Johnson-Sheehan R (2014) Framing and re-framing in environmental science: explaining climate change to the public. J Tech Writ Commun 44:3-21

Semenza JC, Ploubidis GB, George LA (2011) Climate change and climate variability: personal motivation for adaptation and mitigation. Environ Heal 10:46-57

Shanahan M (2007) Talking about a revolution: climate change and the media. International Institute for Environment and Development, London

Slovic P (2000) The perception of risk. Earthscan, London

Spence A, Pidgeon NF (2010) Framing and communicating climate change: the effects of distance and outcome frame manipulations. Glob Environ Chang 20:656-667

Sposato R, Pidgeon NF, Whitmarsh L (2014) Adaptation and mitigation - psychological predictors of behaviour intention and policy support. 23rd Conference on International Association of People-Environment Studies, Timisoara

Stern PC (2000) Toward a coherent theory of environmentally significant behavior. J Soc Issues 56:403-424

Vignola R, Klinsky S, Tam J, McDaniels T (2013) Public perception, knowledge and policy support for mitigation and adaption to climate change in Costa Rica: comparisons with North American and European studies. Mitig Adapt Strateg Glob Chang 18:303-323

Whitmarsh L (2008) Are flood victims more concerned about climate change than other people? The role of direct experience in risk perception and behavioural response. J Risk Res 11:351-374

Whitmarsh L (2009) Behavioural responses to climate change: asymmetry of intentions and impacts. J Environ Psychol 29:13-23

Wolf J, Adger N, Lorenzoni I, Abrahamson V, Raine R (2010) Social capital, individual responses to heat waves and climate change adaptation: an empirical study of two UK cities. Glob Environ Chang 20:44-52

Xenias D, Whitmarsh L, Corner A (submitted) Climate change scepticism as a psychological defence against threatening information. Glob Environ Chang

Zia A, Todd AM (2010) Evaluating the effects of ideology on public understanding of climate change science: how to improve communication across ideological divides? Public Underst Sci 19:743-761 